\title{
Vila Penteado, o "manifesto"
}

\author{
Élide Monzeglio \\ Guilherme Felipe Toscano \\ Jane Victal Duduch \\ Miriam Dardes de Almeida Castanho \\ Roberto Gomide Collet e Silva \\ João Alfredo Barcellos \\ Milton Francisco Junior \\ Wilson Nívio Tessitore
}

Prof ${ }^{2}$ Titular Programação Visual e Comunicaçāo Visual-FAUUSP

Alunos de mestrado-FAUUSP

Alunos especiais da disciplina Mensagens Visuais Integradas (AUP-826) PG FAUUSP
O edifício de valor histórico e cultural Vila Penteado situado na rua Maranhão 88, abriga hoje a sede do curso de pós-graduação da Faculdade Arquitetura e Urbanismo da USP Seu estado de conservação inspira cuidados, sendo que recentemente sofreu desabamentos de parte da estrutura do forro. O esforço de restauro das partes internas, principalmente a recuperação das pinturas que até recentemente se encontravam totalmente cobertas por tinta branca, deu-nos uma mos tra da raridade do expressivo exemplar Art Nouveau na cidade paulistana.

Na disciplina "Mensagens Visuais Integradas" lecionada no $2^{2}$ semestre / 1994, sob a responsabilidade da Prof ${ }^{a} \mathrm{Dr}^{\mathrm{a}}$ Élide Monzeglio, uma equipe de trabalho resolveu aproveitar a ocasião para desenvolver uma campanha de sensibilização da comunidade acadêmica, da opinião pública e principalmente da classe empresarial, frente à importância de unir esforços no sentido da viabilização técnica e financeira para uma ação de abrangência efetiva do restauro deste edifício.

\footnotetext{
Abstract

The historical and cultural building "Vila Penteado" located at St. Maranhão 88, is where the graduate course of Architecture and Urban Design of the São Paulo University takes place nowadays. Its maintenance conditions inspire caution, for example: recently it suffered the falling of part of its ceiling. The restoration of part of the interior, basically the paintings that where covered by white paint, showed the value of the São Paulo's Art Nouveau expression.

In the discipline "Integrated Visual Images" under the responsibility of $\operatorname{Prof}^{\mathrm{a}} \mathrm{Dr}^{\mathrm{a}}$ Élide Monzeglio, a group of students decided to make a campaign to move the academic community, public opinion and more specifically the businessman for the importance of gather efforts in accomplishing effective action towards the building restoration.
} 


\section{Figura 1}

Fachada principal da Vila Penteado, antiga frente à av. Higienópolis, hoje sede dos cursos de pós-graduação da Faculdade de Arquitetura e Urbanismo da Universidade de São Paulo - FAUUSP

Desenho de Wilson Nivio Tessitore
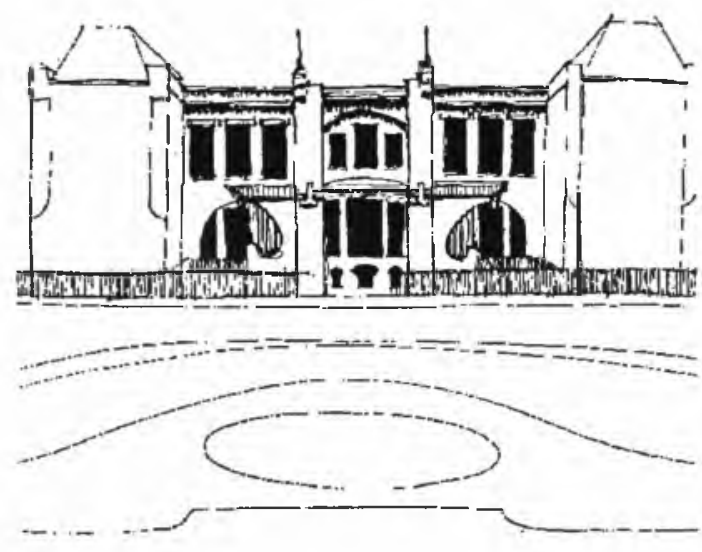

Figura 2

Detalhe da entrada principal, acesso. Peitoril com fechamento em ferro trabalhado e corrimão em madeira.

Desenho de Wilson Nívio Tessitore

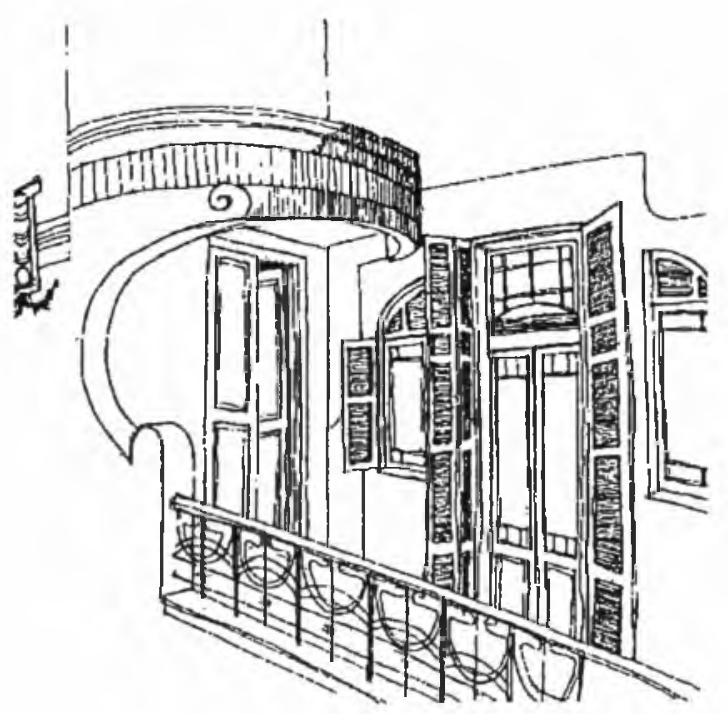

Pós R. Prog. Pós-Grad. Arquit. Urb. FAUUSP, São Paulo, n.5 p. 33-48 abr. 1995

\section{Abertura}

O espírito de criação, de movimento, do irrequieto na natureza humana surge novamente em situação viva aos olhos de todos.

Talvez uma forte ação da união do pensamento único que norteia esse impulso: de um manifesto.

Manifesto que agrega um misto de tristeza, revolta e consciência.

Envolvendo muitos arquitetos que compartilham anseios comuns, outros que nunca imaginaram sua própria participação em algo junto daqueles que se preenchem da preservação do patrimônio.

Corre por esses espíritos aquela centelha da iniciativa individual que percebe 0 momento de unir-se aos outros, engrossando cada vez mais um volume de idéias que percorrem o caminho lento rumo às realizações.

Assim se iniciaram grandes manifestos que resultaram em movimentos preciosos para as comunidades.

O manifesto possui a forma máxima que delineia o desenho geral para essas pessoas, o desenho do idealismo, do espírito altivo e imbativel daqueles que lutam e se debatem por suas convicções.

Assim, surge aos poucos, esse impulso das mentes sem barreiras para atingir o correto, o ético, o legitimado pelos altos valores da manutenção do bem comum, do necessário para essa comunidade.

No cimo deste ideal encontramos profícua iniciativa daqueles que insistem em preservar o patrimônio dentro do qual, o do edifício onde está sediada a Faculdade de Arquitetura e Urbanismo da USP, acolhendo os cursos de pósgraduação, em sua antiga construção.

Somos talvez aqueles que irāo se unir aos antigos companheiros que arquejaram no passado, não por falta de coragem, mas por perceberem que suas vozes não mais fizeram eco nas paragens por onde lutavam.

As suas energias se exauriram com o passar do tempo.

Agora, novas fontes de vitalidade se agregam para que haja prosseguimento a esse MANIFESTO.

\section{Colocações sobre a História do Edifício}

Parece hoje redundante falar desta obra de arquitetura que é a Vila Penteado. Tantos já dedicaram a ela esforços para elucidar suas origens e conseqüências, procurando inclusive requalificá-la dentro de novos parâmetros, retirar algum resíduo deste remanescente histórico. A questão é, sendo de origem proletária ou da burguesia ascendente do começo do século, todo paulistano deve reconhecer seu valor, agora que esta expressão da cultura chega às proximidades de um século de existência.

Este exemplo de "Arte Nova" representa, na sua concretude, justamente aquilo que distingue o espirito da cidade, o ideal do progresso vinculado ao trabalho, e o direito de todos a esta aventura.

Nós paulistanos temos uma obscura tendência predatória. Comumente olhamos para o futuro descuidando os laços da origem, procurando o novo absoluto, a 


\section{ste quadro não está na Bienal.}

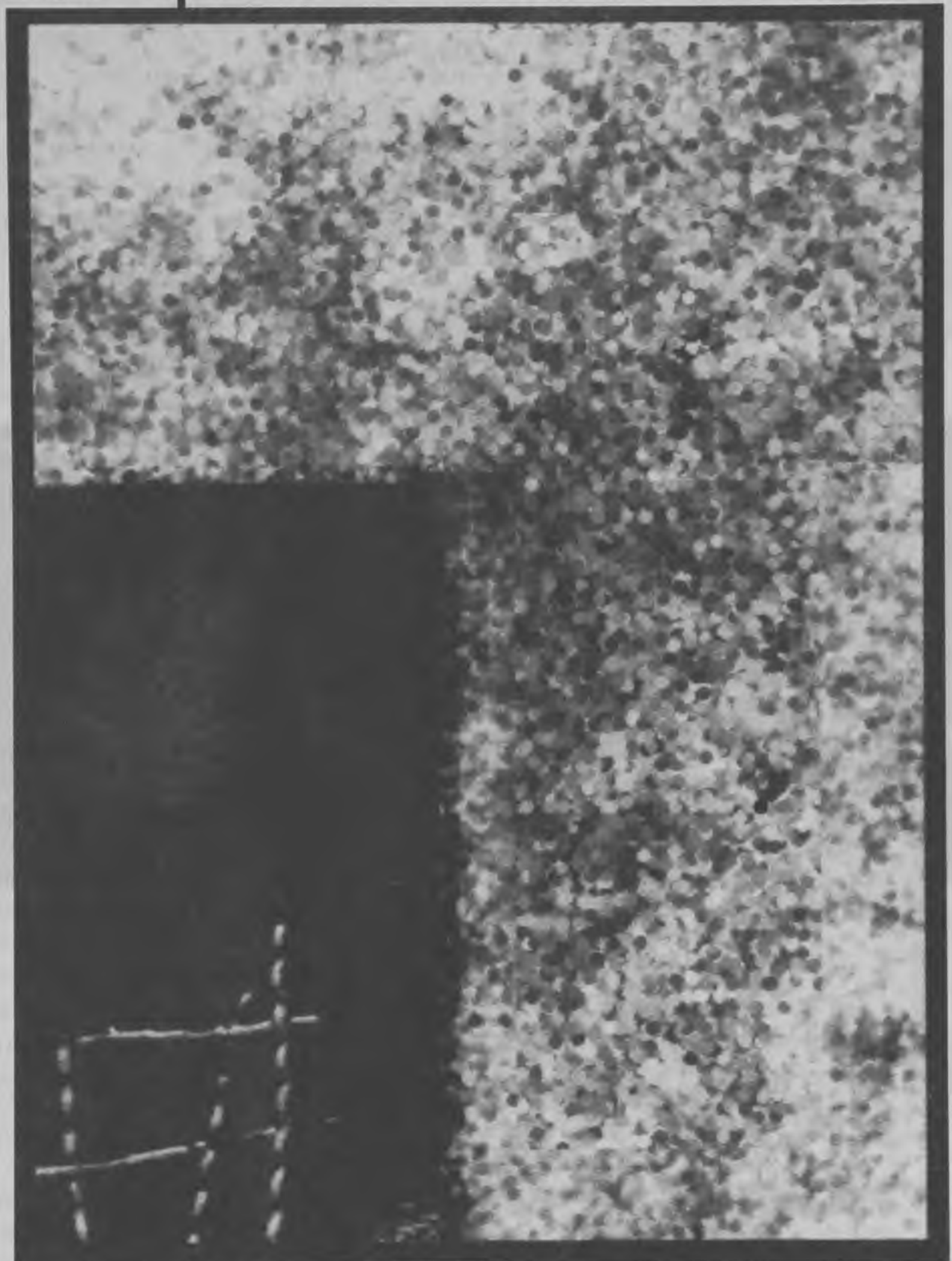

\section{as você não pode deixar de conhecê-lo.}


(1) EKMAN, Carlos. "Recordaçōes de minha vida." In: HOMEM, M. C. N. e MACHADO L., Vila Penteado. São Paulo, FAUUSP, 1976, p. 44.

(2) HOMEM, Maria Cecília N. "Uma família Paulistana". In: Vila Penteado. Op. Cit. p. 59.

(3) DEAN, Warren. "Sāo Paulo em 1900". In: Vila Penteado. Op. cit. p. 22. mudança, o progresso. Foi inclusive esta mentalidade que levou estas duas personalidades - 0 arquiteto e seu patrocinador - no começo do século 20 , a encamparem este projeto que representava então um ideal de renovação dos hábitos da produção tipicamente rural.

Carlos Ekman, o arquiteto sueco responsável pelo projeto desenhado em 1902, era certamente um visionário; assim não fosse não teria deixado a Europa do começo do século e buscado as terras novas das Américas, primeiramente se dirigindo aos Estados Unidos, Nova York, Chicago e outros grandes centros, depois vindo a Buenos Aires para finalmente se estabelecer em São Paulo. Seu pai, também arquiteto e preocupado com a pré-fabricação em madeira das construções, havia perdido toda a fortuna da família numa tentativa de entrar para o ramo industrial; vendera a serraria com a qual fizera fortuna para fundar uma nova fábrica, vindo a falecer quatro anos depois, deixando apenas dívidas. Ekman não tinha nada mais a perder. Os estudos na Escola Técnica de Copenhagen, interrompidos pelo falecimento do pai, tiveram continuidade na Escola Técnica de Stokolmo, no curso especial de Arquitetura e Ornamentação. Nisto consistia sua formação, juntamente com os diversos empregos como desenhista, aqui e ali nas paragens, em percurso extravagante e aventureiro contado brevemente num pequeno texto autobiográfico ${ }^{1}$ Depois de calmarias e aventuras, finalmente chega a São Paulo, esta cidade incansável, a primeira a se industrializar na América Latina. Com rolos de papel desenhado debaixo do braço, encontra os meios para colocar em prática o seu talento de arquiteto.

Antônio Álvares Penteado, pelo contrário, estava em plena ascensão. Provinha de família de fazendeiros abastados da região de Mogi Mirim. Era um idealizador competente e mais que tudo um realizador das suas idéias. Aos 21 anos já demonstrava sinais de grande empreendedor que era, ao transformar as terras doadas por seu pai em fazenda produtora de café, a Fazenda Palmares, e já que era imperativo a abolição do sistema de mão-de-obra escrava, mostrava grande adaptabilidade às mudanças, contratando, sem perda de tempo, mão-de-obra imigrante. Chegou a ter duzentas famílias italianas morando e trabalhando nas suas plantações de café.

Mas não se contentou com a vida rural, queria os centros urbanos e tinha planos industriais. Aos 25 anos, em 1877. fundava a fábrica Santana, que cinco anos depois empregava oitocentos operários, na maioria italianos, e mantinha uma produção diária de setenta e cinco mil metros de tecidos"2. Este era o espírito do conde Antônio Álvares Penteado e seus filhos, que não negaram a sua natureza.

Assim é a cidade de São Paulo, formada por pessoas vindas das zonas rurais ou de outros países, sempre procurando novas oportunidades, olhando para frente, renovando, transformando, adaptando-se às novas solicitações do ambiente e principalmente criando alternativas de expansão da cultura do trabalho. Porém, justamente aquilo que a fortifica, nesta tendência de ir para frente sem olhar para trás, se dá a sua fraqueza, quando despreza as origens e descuida do passado, renovando continuamente as camadas de assentamentos no solo urbano. Quase não há mais remanescentes representativos do Art Nouveau, a Vila permanece como testemunho destas habitações da burguesia ascendente do começo do século.

Na última década do século 19, São Paulo cresceu de 64.000 para 240.000 habitantes num período de apenas dez anos ${ }^{3}$. Era o auge do período do café, 
exportado para os Estados Unidos e Europa pelo porto de Santos, chegando até o mar através da estrada de ferro que, neste período, fora ampliada em $1.300 \mathrm{~km}$. Seus vagões subiam a serra de volta carregados de produtos estrangeiros. Havia grande permeabilidade entre as classes sociais, com ascensāo rápida para quem se dispunha ao trabalho e principalmente a uma mentalidade racional de organização da produção e do comércio. Com o vapor, por água ou por terra, as distâncias se encurtavam como nunca.

Foi nestas condições que arquiteto e patrocinador se juntaram para concretizar um projeto que representava a própria emancipação cultural. Era parte da França aqui; mas contextualizada. Em 1900, Álvares Penteado em viagem a Paris com toda a família, tivera a oportunidade de visitar a Exposição Universal de Paris, destinada à divulgação do movimento Art Nouveau, então em seu apogeu na Europa. Voltando ao Brasil, resolve adotar o estilo em suas construções. Conhecendo o arquiteto Carlos Ekman, contrata-o para o projeto da Vila Penteado.

$\mathrm{Na}$ Europa, a Revolução Industrial trouxera grandes transformações à vida cotidiana e conseqüentemente à produção, às artes e cultura. As técnicas de produção passavam por uma fase de desenvolvimento, enquanto a linguagem estilística ainda carregava a expressão de conteúdos ultrapassados. Os elementos decorativos estavam em descompasso com a revolução tecnológica; pareciam agregados carentes de síntese entre estrutura, forma e função. Passaram a denotar o supérfluo, o desnecessário. Havia a necessidade de encontrar um sistema figurativo que representasse os novos ideais, e principalmente se adequasse à produção mecânica, para que os objetos fossem produzidos em larga escala e portanto democratizados. O estilo Art Nouveau representou um prelúdio ao desenho moderno que surgiria como resposta a estas indagações. Seu apogeu, em 1900, marcado pela Exposição Universal em Paris, é também o princípio de sua decadência para, imediatamente, seguir o surgimento do movimento moderno.

A linha sinuosa e a pureza das formas, a liberdade da planta desvinculada de qualquer historicismo, o uso da estrutura aparente ainda com alguns elementos decorativos para integração ao conjunto de formas e finalmente articulação de volumes num esforço de adequação racionalizada, princípios respeitados por Ekman na Vila Penteado, são características deste novo estilo. A aproximação entre arte e ciência, ou arte e técnica, era o novo ideal representado. Este ideal fora incorporado posteriormente pelos primeiros arquitetos modernistas. Admiradores das máquinas, compreenderam o seu significado, assim como as conseqüências que trariam os arquitetos austríacos Otto Wagner e Adolf Loos, os americanos Louis Sullivan e Frank Lloyd Wright, e o belga Henri van de Velde, que por sua vez foram influenciados por Ruskin e Morris da Inglaterra, o país da industrialização na época. O resultado formal deste novo desenho, chamado modernista, era despojado e livre, surgindo das formas mais simples e puras:

$\mathrm{Na}$ Bélgica, dois arquitetos influenciados pelos Arts and Crafts ingleses, desenvolveram o estilo Art Nouveau de transição: Victor Horta e van de Velde: Pevsner escreve sobre Victor Horta o que segue: "Nas obras deste, sentimos sempre a presença da natureza, seja vegetal ou animal. $O$ desenho de van de Velde é rigidamente abstrato e - pelo menos teoricamente - pretendia ilustrar a função do objeto ou de parte do objeto a que está ligado"4 É precisamente a obra do primeiro, também chamado floral belga, que inspira Carlos Ekman na Vila Penteado. As figuras femininas, begônias, juntamente com a expressão da riqueza nacional da época, ramos de café - e as cenas da evolução industrial nacional, desde o século 15 , com a produção artesanal indígena, a indústria do
Figura 3

Detalhe da entrada principal, varanda em abóbada com acabamento superior lateral.

Desenho de Wilson Nivio Tessifore

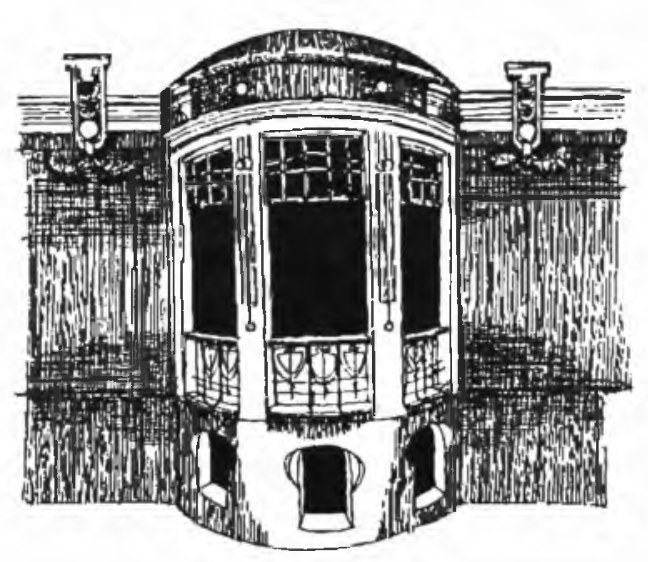

Figura 4

Detalhe de caixilho de madeira do pavimento superior. Venezianas restauradas e laterais com desenho em alvenaria, caracteristico do edifício. Desenho de Wilson Nivio Tessifore

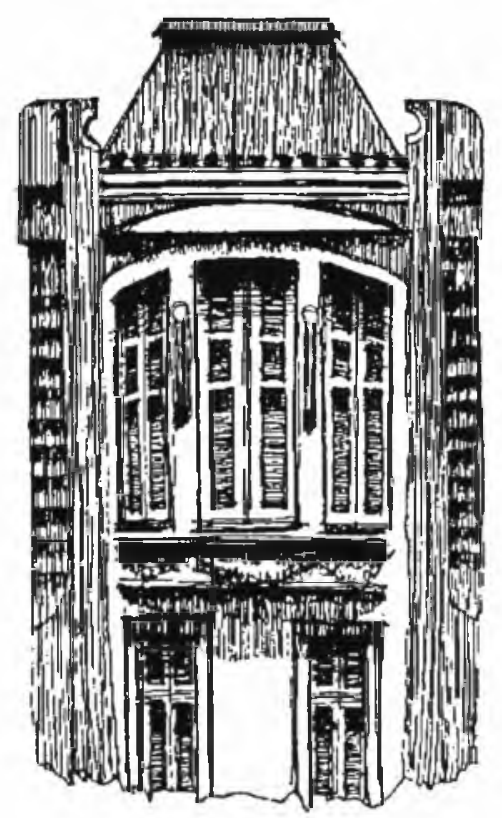

(4) PEVSNER, Nikolaus. Os pioneiros do desenho moderno. 2. ed. Lisboa: Ulisséia, 1948, p. 90. 


\section{Imagens da Vila Penteado}
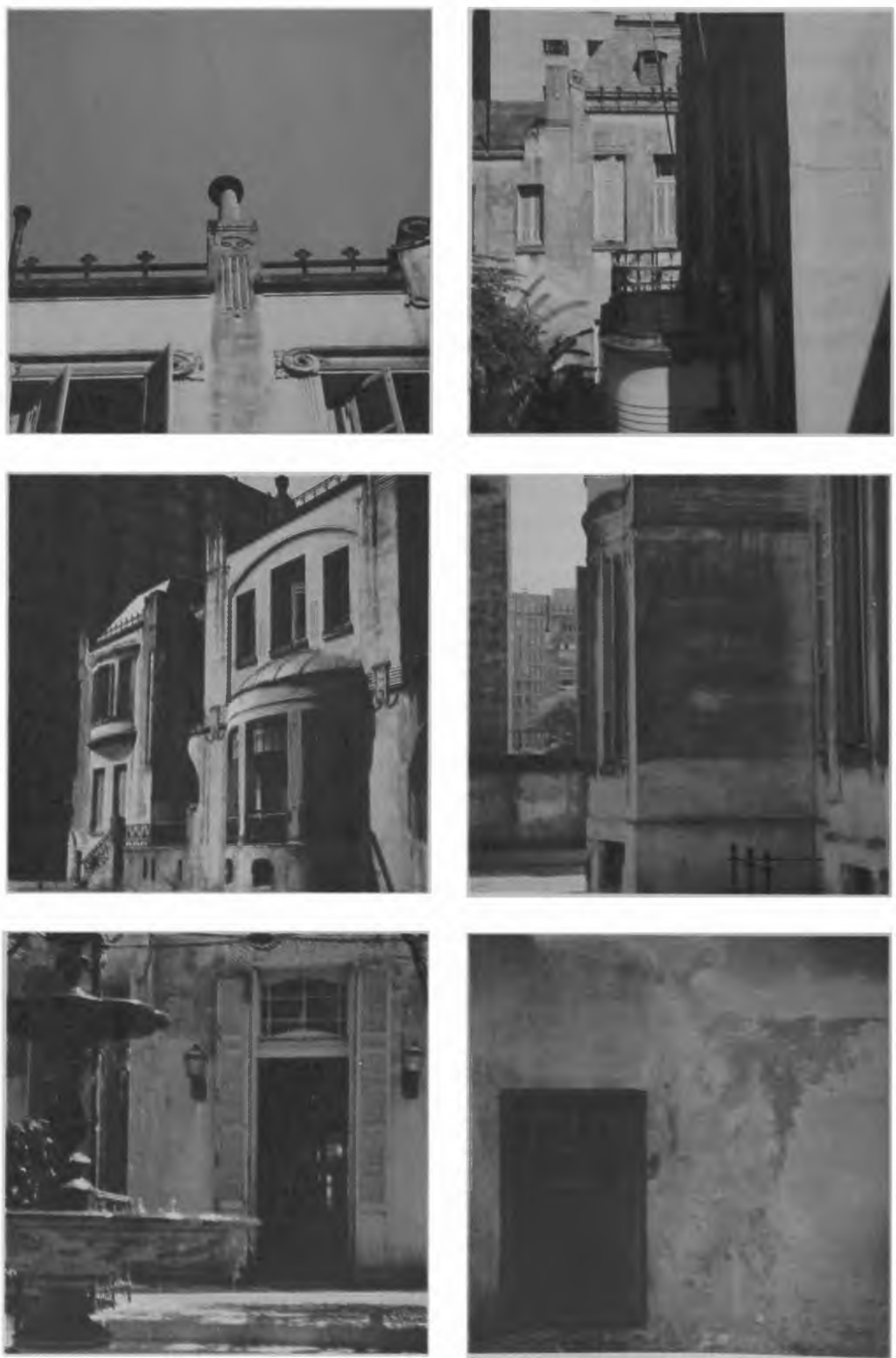

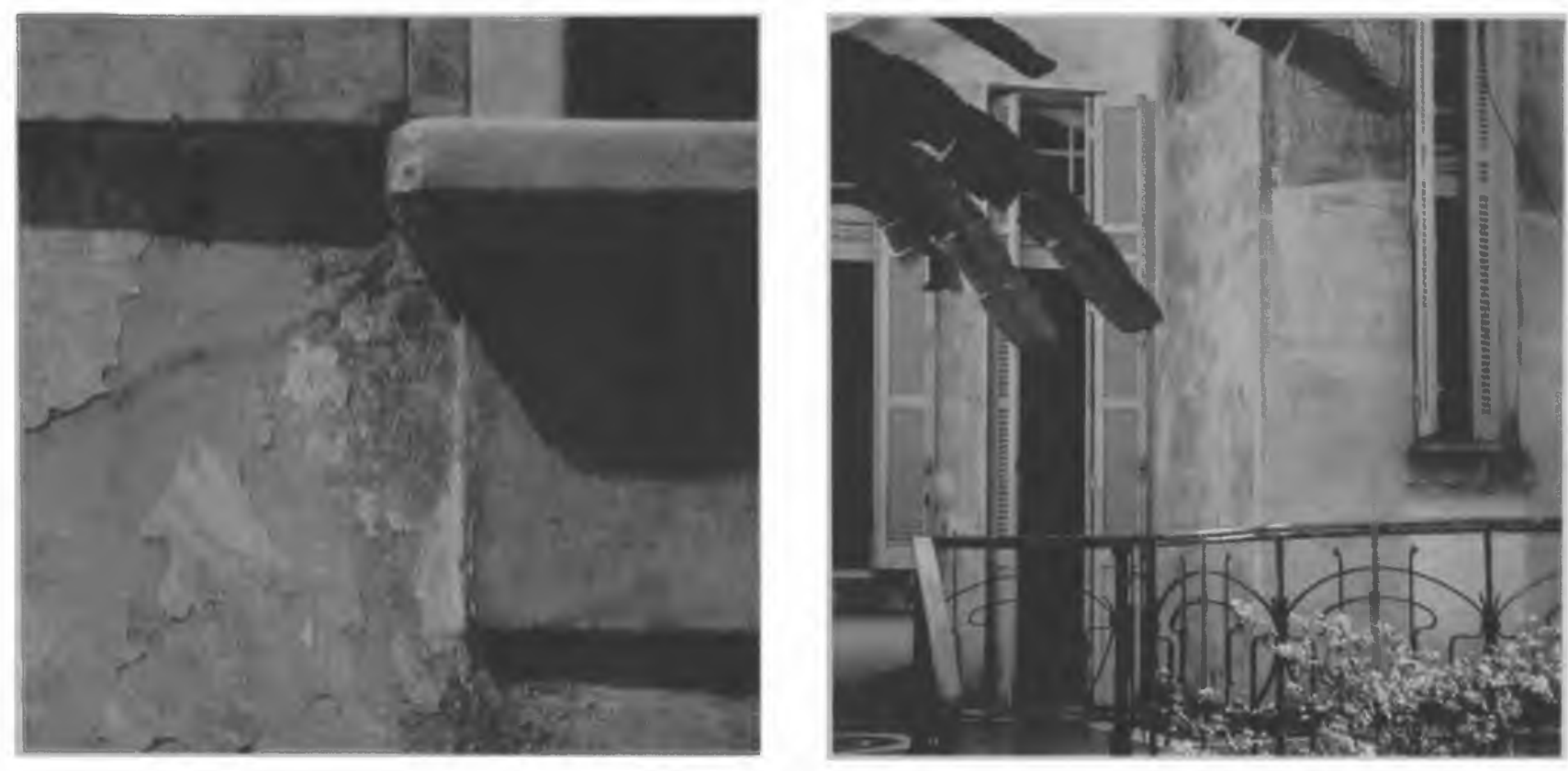

Fotos de Jane Duduch
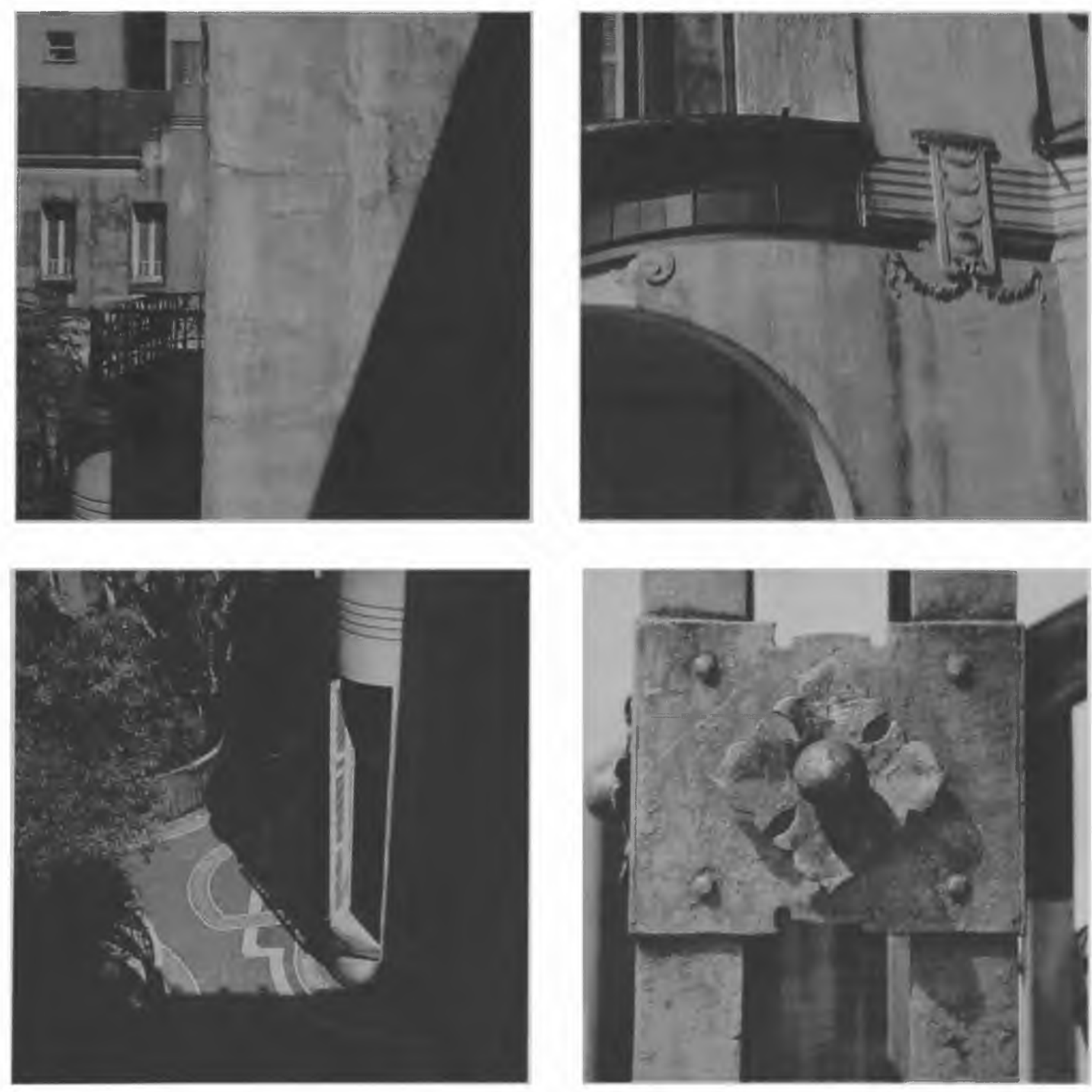
Figuras 5 e 6

Detalhe de figuras ornamentais externas características do edifício, executadas em alvenaria e gesso.

Desenho de Wilson Nivio Tessifore
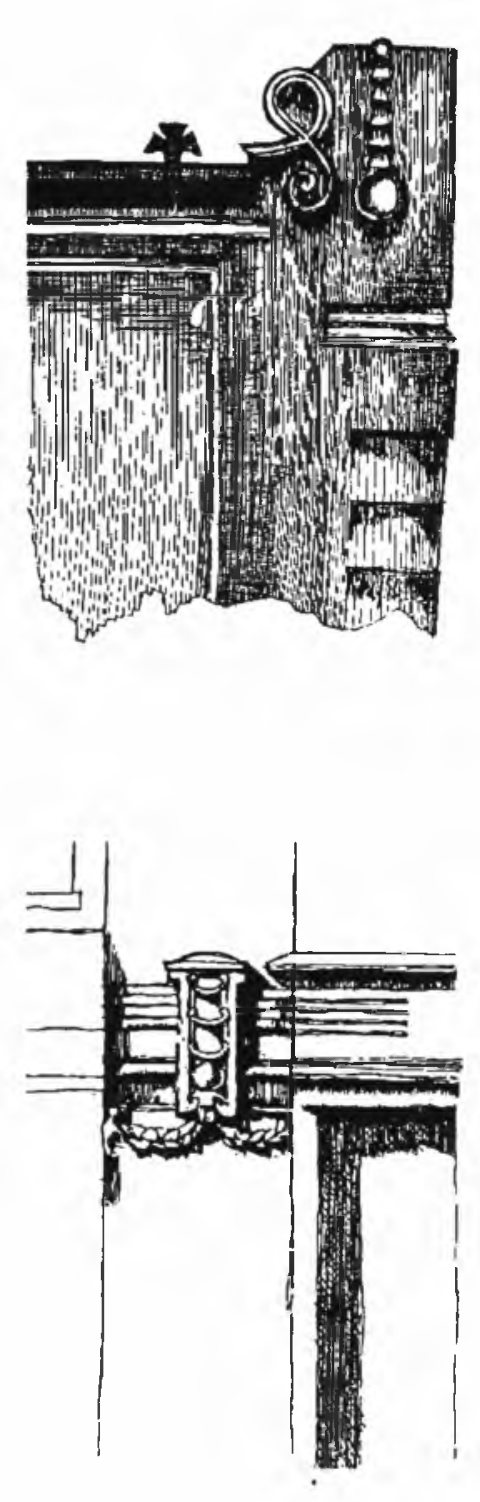

(5) REIS FILHO, Nestor Goulart. "O edifício da Vila Penteado em 1976" In: Vila Penteado. Op. cit., p. 09. século 17. a manufatura têxtil rural, e finalmente a do século 19, uma figura angélica com a fábrica Santana ao fundo, decoram o salão principal, aquele que distribui racionalmente os espaços, numa centralidade simétrica. Uma mistura de culto à natureza e ideal de progresso através da indústria.

Este ideal da produção, da realização de grandes fatos, incluindo a indústria, a arquitetura, a educação, a cultura era próprio do conde Álvares Penteado. Ele foi certamente o representante brasileiro do movimento Art Nouveau na arquitetura da cidade de São Paulo. A Vila Penteado era o seu reduto familiar, seus filhos Sílvio e Armando foram excentricidades paulistanas; envolvidos com automobilismo e aviação, viviam parte em São Paulo, parte em Paris, trazendo as novidades e mantendo o intercâmbio cultural. Quando Armando falece em 1947. ele e o irmão haviam acabado de adquirir as partes pertencentes aos herdeiros da Vila Penteado, fazendo uma doação do edifício à Universidade de São Paulo para o funcionamento da escola de Arquitetura e Urbanismo.

Nas palavras de Nestor Goulart Reis Filho: "Após a instalação da Faculdade de Arquitetura e Urbanismo em 1948, o prédio da 'Vila Penteado' tornou-se centro de um conjunto de programas culturais praticamente sem similares em toda Universidade de São Paulo. ${ }^{5}$ Ali se congregavam os estudantes desta e de outras faculdades para exibições de filmes de arte, conferências e debates sobre arquitetura e artes plásticas. A atitude progressista característica de cidade, permanece ligada ao edifício, mesmo tendo deixado de .pertencer à família Álvares Penteado.

Hoje, 46 anos após a instalação da faculdade nesta localidade, cujo endereço foi alterado da avenida Higienópolis para a rua Maranhão - a entrada principal se dá agora pelo que originalmente era o pátio do jardim interno da residência - . a Vila Penteado inspira cuidados. Necessita de um trabalho efetivo de restauro e readaptação a usos contemporâneos.

Devido à escala desta tarefa, exige o esforço de toda a comunidade, sendo que os recursos técnicos e financeiros superam as possibilidades da classe universitária. Podemos quantificar seu valor histórico, arquitetônico, visando inclusive a sua monumentalidade poética, mas não reunimos os recursos financeiros necessários para uma ação efetiva, capaz de fazer passar o lugar construído ao século 21 O espírito progressista que este sítio e sua edificação emblematicamente simbolizam para a cidade, deveria ser fator suficientemente aglutinador de esforços por parte da classe empresarial.

\section{A Campanha}

A campanha organizou-se a partir das definições dos objetivos do grupo de trabalho, no sentido de se transmitir eficientemente a mensagem. Desta forma procurou-se conferir ao conjunto das peças publicitárias, integrantes da campanha, um impacto compatível com a necessidade imediata de uma intervenção, visto que o edifício apresenta locais com risco de desabamento de algumas estruturas de revestimento, oferecendo portanto um perigo em potencial aos seus usuários.

Assim, montou-se uma campanha de grande impacto, enfatizando a idéia de que a FAU/MARANHÃO não é um edifício que necessita de uma reforma, mas sim um patrimônio histórico de todos, que necessita um restauro.

Buscou-se efetivamente chamar a atenção do público alvo, através da mobilização da sociedade como um todo, ligada ou não à Universidade, e desta maneira 
atingir, direta ou indiretamente, o pequeno grupo que efetivamente detém recursos que possam ser efetuadas as intervençōes necessárias no edifício da FAU/MARANHĀO. Nossa tarefa, segundo uma visão mais objetiva, é mostrar a esse grupo, composto por empresários e representantes de grandes empresas ou instituições, públicas ou privadas, o retorno em imagem que pode ser angariado através da associação da marca do patrocinador com um empreendimento voltado à recuperação de um patrimônio histórico, mais especificamente o prédio da FAU/MARANHÃO.

Nosso enfoque, como já foi mencionado, objetiva associar a imagem de um eventual patrocinador à uma iniciativa de caráter cultural, em troca da divulgação da marca deste patrocinador em eventos, publicações e divulgações do processo de execução do restauro e na utilização da obra acabada. Os conceitos de patrimônio, valor histórico do edifício da FAU e da memória do nosso povo, são colocados em foco para atrair o empresário. Estes realmente configuram-se como os diferenciais que influenciam as decisões e as escolhas, já que o conjunto dos potenciais empresários patrocinadores estão perfeitamente cientes das vantagens fiscais deste tipo de patrocínio.

\section{As Idéias}

A linha mestra de nossa campanha baseia-se em fixar os seguintes conceitos:

- a importância histórica do prédio da FAU-MARANHÃO;

- a situação grave de decadência deste prédio;

- a importância de se preservar nosso patrimônio histórico.

Desta forma, apresentamos uma seqüência de imagens, nas quais partimos de um fragmento da fachada do edifício, tomado fotograficamente em uma ampliação tal que não se permite associá-lo com o edifício. Dada a abstração desta imagem, a campanha leva intencionalmente à associação da mesma com um quadro, uma obra de arte. O nome desta tela fictícia é "O TEMPO". e o autor é "DESCASO" As chamadas reforçam ain da a idéia de que a imagem quadro, introduzindo a idéia da Bienal, como evento fortemente presente e conhecido, e ao mesmo tempo conclamam a necessidade do leitor conhecer este "quadro":

"ESTE QUADRO NÃO ESTÁ NA BIENAL.

\section{MAS VOCÊ NÃO PODE DEIXAR DE CONHECÊ-LO.}

Desta maneira, despertamos o interesse do leitor em saber por quê deve-se conhecer um quadro que, mesmo não estando na Bienal, é chamado a conhecer.

A segunda imagem, seqüência da primeira, já trata a palavra "quadro" não como obra de arte, mas como situação urgente e quase desesperadora. O leitor associa - fragmento à fachada do edifício mostrada na íntegra, notando-se o aspecto decadente. As ambigüidades vão tomando forma e o leitor percebe que o quadro inicial, visto como obra de arte, é na realidade um fragmento do edifício e que o "quadro" que realmente existe é de ameaça à verdadeira obra de arte, que é o edifício histórico.

O slogan final, foi intencionalmente compilado da campanha de um grande jornal, objetivando, na mensagem final, direcionar a força consumista deste slogan, 
talhada na mídia a custos altíssimos, para uma necessidade premente de preservação da nossa memória, do nosso patrimônio histórico:

\section{FAU MARANHÃO. NÃO DÁ PRA NÃO RESTAURAR.}

Esta prática de copiar slogans foi largamente usada, com bastante criatividade, em campanhas do próprio jornal e do seu principal concorrente, na famosa "guerra dos jornais" travada nos campos da propaganda, em que dois grandes formadores de opinião da mídia impressa disputam o leitor palmo a palmo.

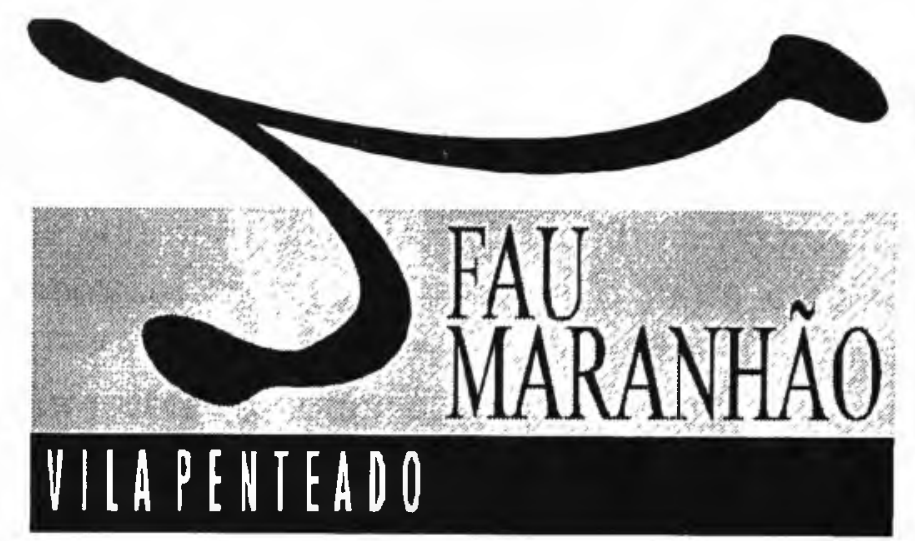

Logomarca para campanha

\section{A Identidade Visual da Campanha}

Para esta campanha foram criados sistemas de identidade através das mensagens escritas (slogans e chamadas) e das mensagens visuais (fotografias e logomarcas).

A logomarca da campanha "FAU/MARANHÃONILA PENTEADO" foi pensada inicialmente com a mesma estrutura da campanha. Os nomes e textos deveriam ser apoiados e integrados por uma estrutura forte, identificada com o conjunto. Esta estrutura, como na campanha, busca o fragmento, o detalhe para representar o todo. A enorme profusão de detalhes belos e significativos salta aos olhos num passeio pela FAU/MARANHÃO.

A difícil escolha recaiu sobre a maçaneta da porta de entrada, que foi desenhada e traçada novamente de modo a integrá-la com a logomarca. No formato de um "F' alusivo à FAU, esta forma caracteriza marcantemente o Art-Nouveau, e integra as inscrições 'FAU/MARANHÃO" e "VILA PENTEADO' num desenho compacto e de grande visibilidade.

Optou-se por diferenciar as referidas inscrições, através da utilização de fundos e tipografias diferentes, evidenciando os dois momentos distintos da vida do edifício.

\section{Mídias}

Para a divulgação da campanha, foram eleitas três mídias que seriam as mais indicadas para se atingir o público alvo:

A primeira foi a apresentação do trabalho da equipe no final do ano letivo de 1994, com a montagem de uma instalação no saguão da FAU/MARANHÃO.

A segunda se inicia com este artigo, onde as peças gráficas, que na instalação eram cartazes, neste colocam-se como páginas que revelam aos poucos, a 
Mesmo decadente, o prédio da FAU Maranhão ainda consegue gerar imagens fragmentárias de rara beleza e poesia.

Mas até quando?

Infelizmente, o "quadro" que se verifica, mais que a pura contemplação de uma obra de arte, é sua urgente preservação.

Tal qual outras edificações, cujo valor tem repousado em ricas significações históricas, artísticas e afetivas, o prédio da FAU Maranhão encontra-se em condições físicas extremamente precárias.

De um lado, insuficientes recursos públicos para sua manutenção e restauro, de outro, o desconhecimento de seu valor histórico cultural.
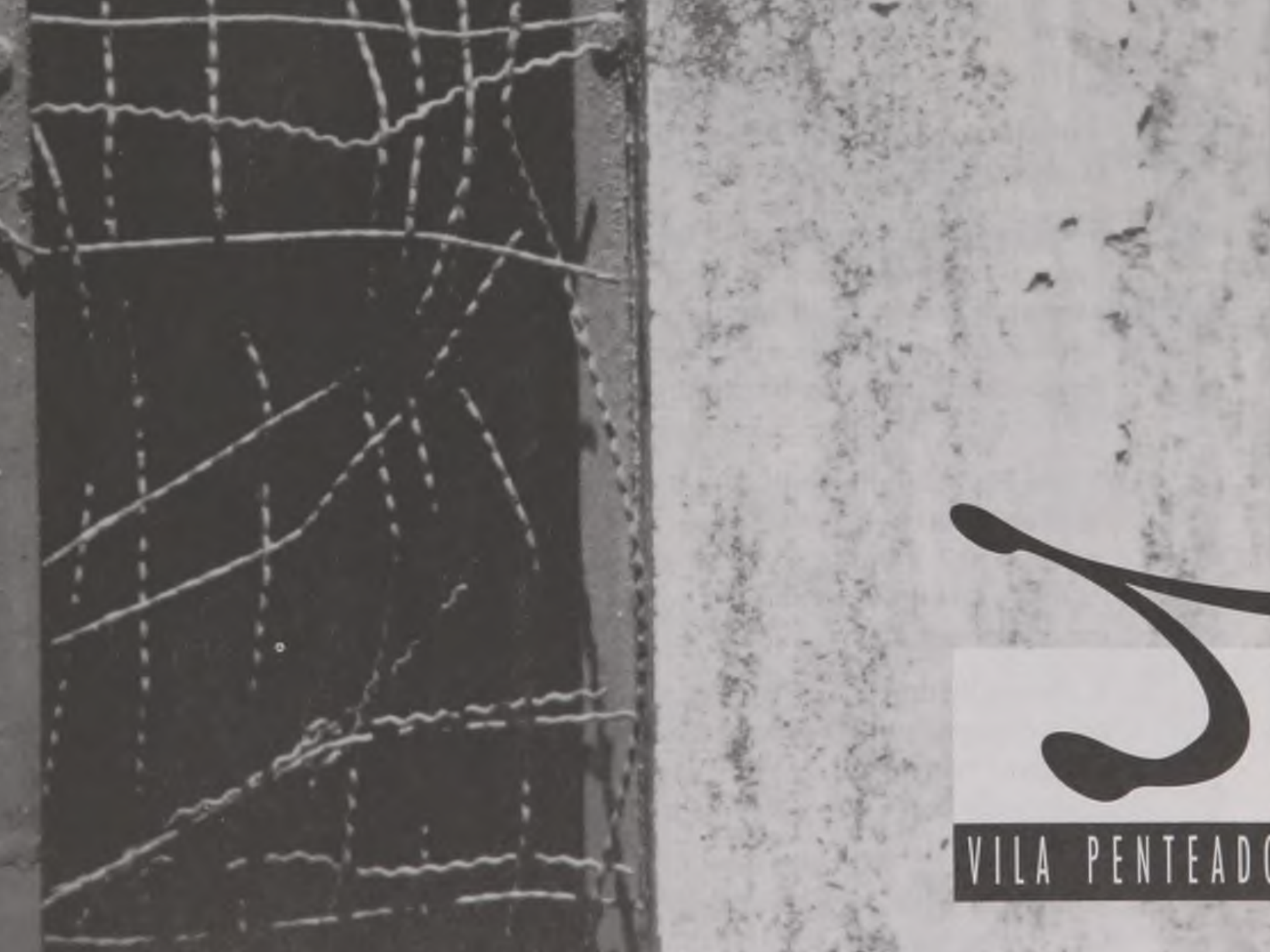

FAU MARANHÃO
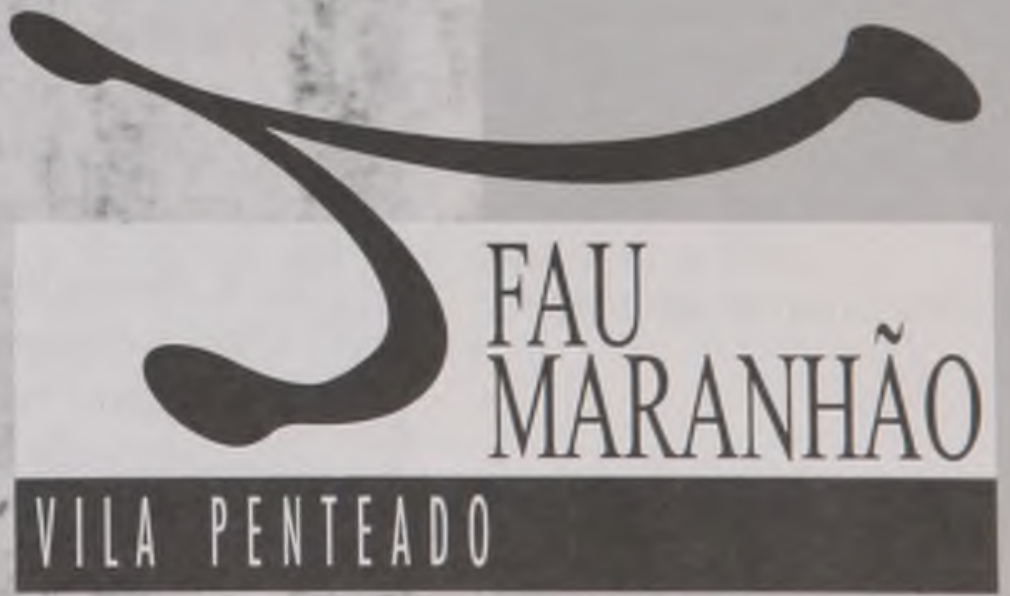
importância de um edifício, e a decadência de uma parte do nosso patrimônio histórico. Pretende-se que estas imagens venham a fazer parte de outras publicações, de circulação mais digirida para a classe empresarial.

E finalmente, a terceira será a divulgação através de um folder de distribuição mais abrangente, em locais estratégicos, freqüentados pela populaçāo formadora de opinião - como teatros, cinemas, galerias, museus, etc. O folder estará funcionando como um reforço de conceito, criando uma consciência da opinião pública, dando amparo à campanha, para que a sociedade civil cobre soluções, e o empresariado se sinta estimulado e respaldado a tomar iniciativas.

\section{A Instalação}

A instalação, como já foi colocado, fez parte da apresentação do trabalho elaborado pela equipe para a disciplina "Mensagens Visuais Integradas", ministrada pela Prof ${ }^{a} \mathrm{Dr}^{\mathrm{a}}$ Élide Monzeglio.

A instalação é uma estrutura metálica que delimita um espaço, onde foram colocados painéis de compensado, telas de nylon, jornais espalhados pelo chão e luzes incandescentes penduradas por fios e soquetes, simulando uma situação de restauro. Neste ambiente, cartazes mostram a decadência do edifício da FAU/ MARANHÄO, contrapondo-se a slides de detalhes e belezas da Vila Penteado.

Através de recursos de luz, som e imagens em movimento, a instalação "estimula" e "convida" o observador para seu interior, sugerindo, com a seqüência de cartazes, o percurso a ser seguido.

Ao final do percurso, o observador, munido com as informações recebidas, conscientiza-se da importância cultural e histórica do edifício e de seu estado de deterioração, iniciando-se nossa campanha.

\section{Considerações sobre o Trabalho Elaborado. Estudos de Pós- Graduação}

Incluído nos estudos de pós-graduação realizados para a disciplina "Mensagens Visuais Integradas" no $2^{\circ}$ semestre de 1994, este tema foi escolhido por corresponder aos objetivos propostos, caracterizando mensagem espacial que integra conhecimentos de forma interdisciplinar, reunindo principalmente: arquitetura e desenho, arquitetura e história, arquitetura e cidade, arquitetura e preservação de patrimônio cultural.

A Vila Penteado sugeriu o tema, pela presença marcante do edifício na rua Maranhão do bairro de Higienópolis, por seu desenho de beleza es tética que nos revela imagem que remonta ao início deste nosso século 20. Momento especial da então arte nova, o estilo Art Nouveau, o traço forte e construtivo arquitetônico conjugado àquele orgânico e sinuoso da natureza vegetal.

O traço com domínio da linha que envolve o volume edificado e nele penetra por seus desenhos decorativos externos e internos, de folhagens, ramagens, flores e frutas, medalhões e rostos em perfís, baixos relevos e pinturas, evidencia o equilíbrio visual entre desenho e espaço arquitetônico.

A presença de sua beleza estética ainda domina o quarteirão, significando um referencial expressivo local, no bairro de Higienópolis, e urbano da cidade de São Paulo. 


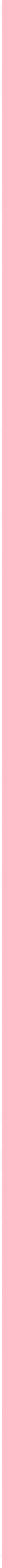


Mesmo com a intervenção seqüente de massas edificadas dos inúmeros prédios ao redor construídos com muitos andares, que foram gradativamente surgindo mudando horizontes e paisagens do bairro, a Vila Penteado por seu conjunto de desenho harmônico mostra unidade visual. Um conteúdo da forma arquitetônica e de luz/cor ambiental que consegue se manter inabalado, remetendo-nos à percepção de sua origem em seu domínio pleno no quarteirão: avenida Higienópolis que foi sua frente, rua Sabará e rua Itambé que foram suas laterais, rua Maranhão que foi o seu fundo, e hoje é sua frente.

Mais do que tudo, o edifício Vila Penteado é uma expressão ímpar de arquitetura em seu estilo, entre os poucos que ain da permanecem em São Paulo, significando um exemplo a preservar, a representar o patrimônio cultural por seu valor histórico e artístico, constituindo parte indissolúvel da imagem da cidade, elemento de formação de sua identidade no período deste século 20 .

Imagem paulista, cujos dados históricos estão descritos no item anterior acima "Colocações sobre a história do edifício"

A imagem da Vila Penteado percorreu a ponte que atravessou o tempo deste século, plantando as fundações de mansão residência, nos seus primeiros anos de vida e, replantando bases de cultura arquitetônica paulis ta e paulistana, nestes anos de décadas que caminham para o fim da era - século 20 .

Como "Mensagem Visual Integrada" um exemplo de referencial, cujo potencial se não mais se descortina no horizonte livre da cidade, permanece como código visual inalterável, mantendo a imagem que é história da própria cidade.

No tempo e percurso pelo século, mudou de significação pelo uso que the foi destinado a partir de 1948. De residência mansão familiar, passou a ser escola de arquitetura.

De Vila Penteado à FAU/MARANHÃO, símbolo da arte arquitetura, que muito ensinou aos alunos que por ela passaram tornando-se arquitetos, e ensina ainda hoje aos que já arquitetos nela se tornam mestres e doutores.

A comunidade da FAUUSP junta-se a este grupo de pesquisadores alunos de pósgraduação e adota a insígnia da campanha de preservação de seu patrimônio:

'NÃO DÁ PRÁ NÃO RESTAURAR!' 


\section{Bibliografia}

EKMAN, Carlos. Recordaçōes de minha vida. In: HOMEM, Maria C. N.; e MACHADO, Lúcio Gomes Vila Penteado. São Paulo: FAUUSP/Secretaria da Cultura, Ciência e Tecnologia do Estado de São Paulo. 1976

HOMEM, Maria Cecília N. Uma família paulistana. In: HOMEM e MACHADO, op. cit. PEVSNER, Nikolaus. Os pioneiros do desenho moderno. $2^{\mathrm{a}} \mathrm{ed}$. Lisboa: Ulisséia, 1948.

REIS FILHO, Nestor Goulart. O edifício da Vila Penteado em 1976. In: HOMEM e MACHADO, op. cit.

O trabalho a que se refere este artigo foi desenvolvido na disciplina AUP 826 - Mensagens Visuais Integradas no $2^{2}$ semestre de 1994.

Participaçōes da equipe:

Jane Duduch: Colocações sobre a História do Edifício.

Élide Monzeglio: Considerações sobre o trabalho elaborado. Estudos de pós-graduação.

Guilherme Felipe Toscano e Miriam Dardes de Almeida Castanho: Peças publicitárias produzidas para o artigo - Projeto e Computação Gráfica

João Alfredo Barcellos: Redação

Milton Francisco Júnior e Miriam Dardes de Almeida Castanho: Projeto gráfico e editoração eletrônica

Guilherme Felipe Toscano: Logomarca 